Article

\title{
Cold Gas Spraying of Solution-Hardened 316L Grade Stainless Steel Powder
}

\author{
Thomas Lindner ${ }^{1, *}\left(\mathbb{D}\right.$, Martin Löbel $^{1}{ }^{1}$, Maximilian Grimm ${ }^{1}\left(\mathbb{D}\right.$ and Jochen Fiebig ${ }^{2}$ \\ 1 Materials and Surface Engineering Group, Institute of Materials Science and Engineering, \\ Chemnitz University of Technology, D-09107 Chemnitz, Germany; martin.loebel.ww@gmail.com (M.L.); \\ maximilian.grimm@mb.tu-chemnitz.de (M.G.) \\ 2 Forschungszentrum Jülich, Institute of Energy and Climate Research (IEK-1), D-52428 Julich, Germany; \\ j.fiebig@fz-juelich.de \\ * Correspondence: th.lindner@mb.tu-chemnitz.de
}

check for updates

Citation: Lindner, T.; Löbel, M.; Grimm, M.; Fiebig, J. Cold Gas Spraying of Solution-Hardened 316L Grade Stainless Steel Powder. Metals 2022, 12, 30. https://doi.org/ $10.3390 /$ met12010030

Academic Editors: Pasquale Cavaliere and Wei Zhou

Received: 19 November 2021 Accepted: 22 December 2021 Published: 24 December 2021

Publisher's Note: MDPI stays neutral with regard to jurisdictional claims in published maps and institutional affiliations.

Copyright: (c) 2021 by the authors. Licensee MDPI, Basel, Switzerland. This article is an open access article distributed under the terms and conditions of the Creative Commons Attribution (CC BY) license (https:// creativecommons.org/licenses/by/ $4.0 /)$.

\begin{abstract}
Austenitic steels are characterized by their outstanding corrosion resistance. They are therefore suitable for a wide range of surface protection requirements. The application potential of these stainless steels is often limited by their poor wear resistance. In the field of wrought alloys, interstitial surface hardening has become established for simultaneously acting surface stresses. This approach also offers great potential for improvement in the field of coating technology. The hardening of powder feedstock materials promises an advantage in the treatment of large components and also as a repair technology. In this work, the surface hardening of AISI 316L powder and its processing by thermal spraying is presented. A partial formation of the metastable expanded austenitic phase was observed for the powder particles by low-temperature gas nitrocarburizing. The successful deposition was demonstrated by cold gas spraying. The amount of expanded austenitic phase within the coating structure strongly depends on the processing conditions. Microstructure, corrosion and wear behavior were studied. Process diagnostic methods were used to validate the results.
\end{abstract}

Keywords: thermal spray; cold gas spraying; cold spray; thermochemical treatment; powder; austenitic stainless steel; expanded austenite; S-phase

\section{Introduction}

The excellent corrosion resistance of stainless steels contributes to several wide-ranging surface protection applications. Nickel stabilizes the paramagnetic austenitic grades that offer the best performance. Because of the comparatively soft and ductile matrix, similar material pairings have to be avoided due to the risk of cold welding. In addition, tribological loads often cause short service lives of the components. In order to provide adequate surface protection under superimposed stresses, the property profile of these materials can be improved by solution hardening. For applications where an adequate corrosion resistance is required, interstitial hardening is preferred over precipitation hardening. Carbon or nitrogen diffuses into the interstices, while chromium is still dissolved in the solid solution $[1,2]$. Hence, the corrosion resistance is maintained. The elemental enrichment of the surface layer results in strong compressive residual stresses [3]. Additionally, a significant increase in hardness and wear resistance is achieved. A successful enrichment has already been demonstrated in wrought alloys [1-3]. The first results on precipitation hardening by thermochemical treatment of thermal spray coatings were obtained by Nestler et al., while Wielage et al. demonstrated interstitial hardening of coating systems [4,5]. Additional studies demonstrate the general feasibility of coating treatment by thermochemical processes in the low-temperature range [6-12]. While the success of diffusion treatment generally depends on the surface activation, Lindner et al. demonstrated that this is not required in the case of thermally sprayed AISI 316L coatings. The heterogeneous formation of the passive layer is stated as a possible reason [11]. The expanded austenitic layer in porous coating systems can exceed the thickness achieved for wrought material. This is related to 
the penetration of gaseous treatment media [12]. With regard to the lattice parameters, a similar lattice expansion was demonstrated for thermally sprayed coatings compared to wrought alloys.

An alternative approach for the treatment of components is the solution hardening of feedstock materials for the coating process. Particle diameters below $60 \mu \mathrm{m}$ allow for a complete interstitial diffusion enrichment. The successful powder treatment and its processing promises solutions in the field of repair of worn components with an expanded austenitic surface layer. For large components, an economical opportunity for partial or complete coating can be developed. Various approaches to nitride steel powder have been investigated [13,14]. Lindner et al. successfully demonstrated S-phase formation in austenitic steel powder. In order to retain the metastable phase, further processing of the powder requires a sufficiently low process temperature. The subsequent powder processing by thermal spraying revealed the transfer of the expanded austenite to the coating. In comparison with atmospheric-plasma-sprayed and high-velocity-flame-sprayed AISI 316L coatings, it was shown that increasing thermal energy input reduces the lattice expansion [15]. However, an expanded austenitic phase was still detected for both coating systems. A suitable method for the further reduction in the thermal load of the feedstock material is cold gas spraying (CGS). A process gas, typically nitrogen, helium or a mixture of both, with a temperature of several hundred degrees and a pressure of a few $\mathrm{MPa}$ is used to accelerate the particles to velocities between 400 and $1200 \mathrm{~m} / \mathrm{s}$. In contrast to other thermal spray techniques, the powder particles possess a high kinetic energy but moderate temperatures and are solid during the impact on the substrate. The relatively low process temperature offers several advantages: (i) in-flight oxidation of powder particles is avoided; (ii) phase transformation, e.g., the formation of brittle phases, is hindered; (iii) low thermal stresses are present in cold-sprayed coatings [16-18]. CGS coating formation depends on the deformation capacity of the powder feedstock material. A widely accepted explanation for the bonding mechanism in cold gas spray is the adiabatic shear instability as described by Assadi et al. [19] and Grujicic et al. [20]. For a successful deposition, the particles have to exceed a material-dependent critical velocity. A generalized deposition window, determined by critical and erosion velocity, was introduced by Schmidt et al. [21,22] based on fluid dynamics simulations, finite element analysis and experimental validation. Analytical descriptions of for the material- and particle-size-dependent critical velocities were developed and allow us to estimate the deposition window for a variety of metals and alloys [19,21-23]. Austenitic steels are ideally suited due to their ductile behavior. Several authors $[8,24,25]$ have studied cold gas spraying of AISI 316L steel, and different aspects were investigated. Al-Mangour et al. analyzed the influence of heat treatments on the microstructure and mechanical properties of cold-sprayed AISI 316L steel, which demonstrated an increase in tensile strength and ductility after heat treatments [24]. Furthermore, the authors found dense coatings with low porosity when helium was used as a propellant gas. Xie et al. found an increase in the adhesion strength by increasing the substrate pre-heating temperature [25]. The effects of gas temperature and gas pressure of nitrogen on the deposition behavior of AISI 316L coatings were studied by Adachi and Ueda. An increase in gas temperature and gas pressure significantly reduces coating porosity, but at high gas temperatures slightly reduces the coating hardness [8].

In the presented study, precipitation-free hardening by interstitial solvation of carbon and nitrogen was performed for the feedstock material in combination with coating production by CGS. This work contributes to a better understanding of the requirements of surface-hardened powders for CGS by linking the processing and coating properties.

\section{Materials and Methods}

Gas-atomized AISI 316L powder (GTV Verschleissschutz GmbH, Luckenbach, Germany) with a specified particle size of $-53+20 \mu \mathrm{m}$ was used. The particle size distribution was examined by laser diffraction analysis in a Cilas 930 device (Cilas, Orléans, France). In order to obtain an expanded austenitic phase modification by interstitial diffusion enrich- 
ment, an industrial low-temperature gas nitrocarburization treatment was conducted at a temperature below $450{ }^{\circ} \mathrm{C}$ and a duration time of $30 \mathrm{~h}$. Because of the low weight of the powder particles, the risk of them whirling within the gas flow increased. Therefore, the powder was added to a vessel up to a fill level of $50 \mathrm{~mm}$. The coatings were deposited on stainless steel AISI 316L sheets with a thickness of $2 \mathrm{~mm}$. The substrates were ground with $\mathrm{SiC}$ paper up to a 1200 mesh and subsequently polished with a diamond solution in the final step with $3 \mu \mathrm{m}$ diamond solution. Subsequently, the substrates were cleaned in an ultrasonic ethanol bath for $10 \mathrm{~min}$. Coating deposition was conducted using an Impact 5/11 high-pressure cold gas spray system (Impact Innovations GmbH, Rattenkirchen, Germany) equipped with the standard water-cooled D-24 de-Laval-type converging-diverging nozzle. Nitrogen and helium were used as propellant gas. The inlet gas pressure and the temperature were varied in the range of $4-5 \mathrm{MPa}$ and $850-1100{ }^{\circ} \mathrm{C}$, respectively. The standoff distance from the nozzle exit to the substrate surface was $30 \mathrm{~mm}$. The coating was applied in five passes with a spray angle of $90^{\circ}$. Variations in process parameters are summarized in Table 1 . The parameter selection is based on publications on cold gas spraying of AISI 316L steel [8,24,25].

Table 1. Cold gas spraying (CGS) parameters of AISI 316L with Impact 5/11 system.

\begin{tabular}{ccc}
\hline Temperature $\left({ }^{\circ} \mathbf{C}\right)$ & Pressure (Bar) & $\mathbf{N}_{\mathbf{2}}$ /He Ratio $(\% / \%)$ \\
\hline 850 & 40 & $100 / 0$ \\
950 & 40 & $100 / 0$ \\
1100 & 50 & $100 / 0$ \\
1100 & 50 & $75 / 25$ \\
\hline
\end{tabular}

A Cold Spray Meter (CMS) system (Tecnar Automation Ltée, Saint-Bruno-de-Montarville, QC, Canada) was used to determine the state variables of the feedstock during processing. The particles are irradiated in-flight by a laser beam with a wavelength of $790 \mathrm{~nm}$ and a power of $3.3 \mathrm{~W}$. An optical sensor detects the light reflected by the particle surface. In front of the optical sensor, a double-slit mask is placed. If a particle passes in front of the mask, the reflected laser light will result in a double-peak signal. The time of flight (TOF) of the particles is the time passed between the maxima of the two peaks. With the known dimensions of the mask, namely the distance between the middle of the two slits, the magnification of the lens and the TOF of the particle velocity can be calculated. Further details can be found in literature [26-28]. For a stand-off distance of $30 \mathrm{~mm}$, the analysis of the particle velocity was performed on the basis of 10,000 individual particles for all process parameters listed in Table 1 . The particle velocities were filtered between 400 and $1200 \mathrm{~m} / \mathrm{s}$. In addition, the thermal and kinematic states during impact were determined as a function of particle size, using the KSS software.

The surface of the coated samples was ground up to mesh 1000, resulting in a final coating thickness of approximately $200 \mu \mathrm{m}$. Metallographic cross-sections were prepared according to standard metallographic procedures. For the visualization of different microstructural domains, the cross-sections were etched using a Beraha-II color etchant. The resulting contrast enables the evaluation of diffusion-enriched areas regarding their presence and distribution. For the metallographic investigations, an optical microscope GX51 equipped with a SC50 camera (Olympus, Shinjuku, Japan) was used.

A phase-selective hardness measurement was carried out by nanoindentation. For this, a Fischerscope HM 2000 XYp (Helmut Fischer GmbH, Sindelfingen, Germany) with a Vickers tip was used for progressive measurement with a load of $50 \mathrm{mN}$. Borosilicate glass BK7 was used as the calibration standard. Phase analyses were conducted by X-ray diffraction (XRD) using a D8 DISCOVER diffractometer (Bruker AXS, Billerica, MA, USA) with Co- $\mathrm{K}_{\alpha}$ radiation (tube voltage: $40 \mathrm{kV}$; tube current: $40 \mathrm{~mA}$ ). The diffractometer was equipped with polycap optics for beam shaping, a $1 \mathrm{~mm}$ pinhole collimator and a $1 \mathrm{D}$ Lynxeye XE (Bruker AXS, Billerica, MA, USA) detector. All of the diffractograms were measured in a diffraction angle $(2 \theta)$ range from $20^{\circ}$ to $120^{\circ}$, with a step size of $0.01^{\circ}$ and 
$1.5 \mathrm{~s} / \mathrm{step}$. Because of the use of the 1D detector, this value corresponds to $288 \mathrm{~s} / \mathrm{step}$. The powder diffraction file (PDF) database from 2014 was applied for the phase identification and for the determination of the lattice parameters.

In order to investigate tribological behavior under abrasive wear conditions, scratch tests were carried out using a CSM Revetest-RST device (CSM Instruments SA, Peseux, Switzerland). The applied parameters are summarized in Table 2. Tactile measurements using the truncated diamond cone tip of the wear-testing device with a load of $0.9 \mathrm{~N}$ were performed in order to measure the wear marks.

Table 2. Scratch test parameters.

\begin{tabular}{cccccc}
\hline Mode & Force & Speed & Length & Tip & Radius \\
\hline progressive & $1-200 \mathrm{~N}$ & $2.5 \mathrm{~mm} / \mathrm{min}$ & $5 \mathrm{~mm}$ & truncated diamond cone & $200 \mu \mathrm{m}$ \\
\hline
\end{tabular}

The corrosion behavior was investigated by polarization curves, with the aim of studying the effects of different coating microstructures on corrosion current density. A round surface with a diameter of $10 \mathrm{~mm}$ was tested with a three-electrode arrangement. A newly developed $0.6 \mathrm{M} \mathrm{NaCl}$ gel electrolyte with a custom designed corrosion cell was used for the measurements. A platinum sheet with dimensions $\left(2 \times 2 \mathrm{~cm}^{2}\right)$ was used as the counter electrode and a platinum wire was used as the pseudo-reference electrode. After a 30 min measurement of the open-circuit potential (OCP), the polarization curves were examined at a scanning speed of $1 \mathrm{mV} / \mathrm{s}$ in the potential range from $-100 \mathrm{mV}$ to $+500 \mathrm{mV}$ based on the OCP. The experiments were performed at room temperature and were recorded with a potentiometer Zennium (Zahner-Elektrik GmbH \& Co. KG, Kornach, Germany). The polarization curves were evaluated by an MatLab script using the ButlerVolmer equation to determine $i_{\text {corr }}$ and $E_{\text {corr }}$. Due to the immobility of the electrolyte, the corrosion behavior in the immediate surface area was able to be characterized. This is beneficial for a more accurate analysis of real corrosion processes, such as those under biological films, as penetration of the corrosion medium into the coating and contacting of the substrate material can be avoided compared to investigations with liquid electrolytes.

\section{Results}

Because of interstitial solution hardening, the corrosion behavior of the material changes. Hence, applying a Beraha II etching to the cross-section of the solution-hardened AISI 316L powder reveals the detection of the expanded austenitic phase. Figure 1 shows the etched cross-section of the solution-hardened AISI 316L powder. A multiphase state with phase fractions of the metastable expanded the austenitic phase and the initial fcc phase is detected. A deposition of color only occurs at the initial phase. While some particles exhibit complete interstitial hardening, an enrichment limited to the surface area is detectable in the majority of the powder. This can be attributed to the lack of circulation of the enrichment medium during gas nitrocarburizing in the vessel. In addition, deposits of carbon can be partially found on the particle surface, which further impedes circulation and enrichment. The treatment of the powders caused an increase in the characteristic values of the particle size distribution with $d_{10}=29 \mu \mathrm{m}, d_{50}=62 \mu \mathrm{m}$ and $d_{90}=43 \mu \mathrm{m}$. The determined hardness values confirm the heterogeneous state of the powder. The results show that the direct transfer of existing treatment routines to powder materials is impossible. Nevertheless, an enrichment of the powder is achieved, which is suitable for investigating the basic suitability for cold gas spraying. A coating deposition could be achieved with all investigated process parameters. 


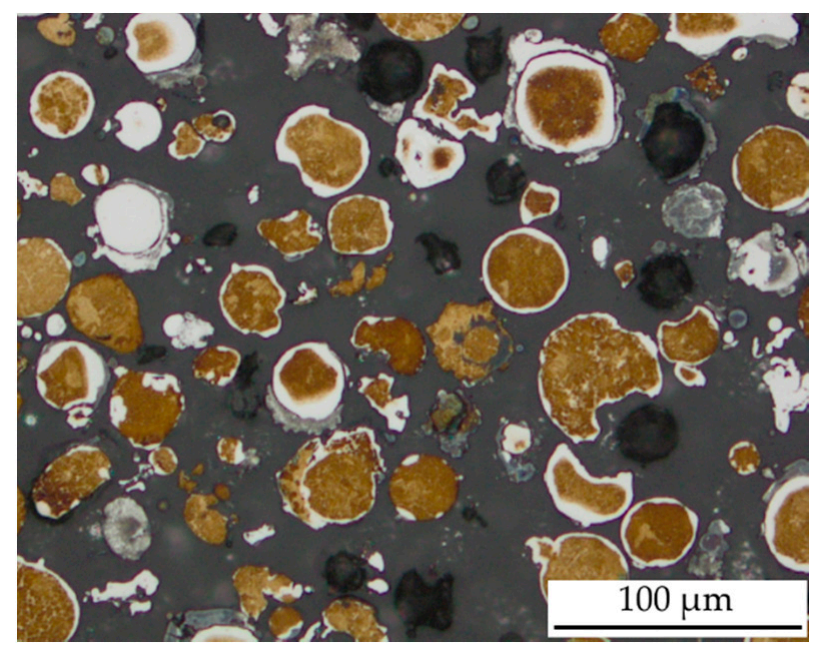

Figure 1. Optical-microscopic image of Beraha-II-etched AISI 316L powder feedstock after gas nitrocarburization.

For example, for the particle sizes of $15 \mu \mathrm{m}$ and $35 \mu \mathrm{m}$, the mean values of the measurement results of the kinematic and thermal state variables are summarized in Table 3. A steady increase in particle temperature and velocity with increasing process temperature can be seen. By adding $25 \%$ He to the process gas, the particle temperature at impact can be lowered. Hence, the particle temperatures exceed the stability limit of the expanded austenitic phase for long-term stress. Due to the very short residence times within process gas, no impairment of the phase stability can be assumed.

Table 3. Impact temperature and velocity of the AISI 316L particles depending on the coating parameters during cold gas spraying. The values were calculated with the KSS software. For the experiments with the cold spray meter, the average particle velocities and standard deviations are listed.

\begin{tabular}{|c|c|c|c|c|c|}
\hline \multirow{2}{*}{ Parameter Setting } & \multicolumn{2}{|c|}{ Impact Speed (m/s) } & \multirow{2}{*}{ CSM } & \multicolumn{2}{|c|}{ Impact Temperature $\left({ }^{\circ} \mathrm{C}\right)$} \\
\hline & $15 \mu \mathrm{m}$ & $35 \mu \mathrm{m}$ & & $15 \mu \mathrm{m}$ & $35 \mu \mathrm{m}$ \\
\hline $850^{\circ} \mathrm{C}$ & 706 & 612 & $717 \pm 106$ & 422 & 618 \\
\hline $950^{\circ} \mathrm{C}$ & 734 & 629 & $775 \pm 114$ & 487 & 699 \\
\hline $1100{ }^{\circ} \mathrm{C}$ & 782 & 680 & $796 \pm 114$ & 575 & 814 \\
\hline $1100{ }^{\circ} \mathrm{C}, 25 \% \mathrm{He}$ & 860 & 726 & $863 \pm 121$ & 489 & 749 \\
\hline
\end{tabular}

The measured and calculated particle velocities differ significantly from each other, Figure 2. Furthermore, all CSM measurements lead to a standard deviation of more than $100 \mathrm{~m} / \mathrm{s}$, see Table 1 . Several factors could be responsible for the enhanced particle velocities. Firstly, during the CSM experiments no substrate was placed in front of the nozzle exit. Due to this setup, the bow shock effect, which mainly affects small and light particles at short stand-off distances [29], is avoided and the measured particle velocities should be compared to those in a free gas stream. The effect is small for the used feedstock, since most particles are larger than $29 \mu \mathrm{m}$. Furthermore, several studies [30-33] have demonstrated that particle measurements with DPV systems (including CSM) typically lead to higher average velocities than CFD simulations. Increases of up to $8 \%$ were reported, corresponding to a velocity enhancement of 40 to $60 \mathrm{~m} / \mathrm{s}$ for the experiments carried out in this work. Nevertheless, the deviations in the current study are significantly higher, which might be related to the non-spherical shape of a portion of the feedstock, as it can be seen from the cross-section images in Figure 1 and in Figure 2 [15]. A recent study by Özdemir et al. [34] has demonstrated the importance of considering the particle shape when comparing particle velocities obtained by CFD simulations with experimental results from velocimetry. For non-spherical particles, other models for the drag coefficient are incorporated in the calculations, resulting in higher particle velocities. Özdemir et al. 
replaced the drag coefficient given by Schiller-Naumann [35] with the drag coefficient of Haider and Levenspiel [36]. This model includes a shape factor, called sphericity $\psi=\mathrm{s} / \mathrm{S}$. ( $\mathrm{s}=$ Surface Area of a Spherical Particle of Equivalent Volume)/S = Surface Area of the Particle Under Investigation), which was introduced by Wadell [37]. For a sphere the sphericity parameter is equal to 1 , and for non-spherical particles the parameter is smaller than 1 .

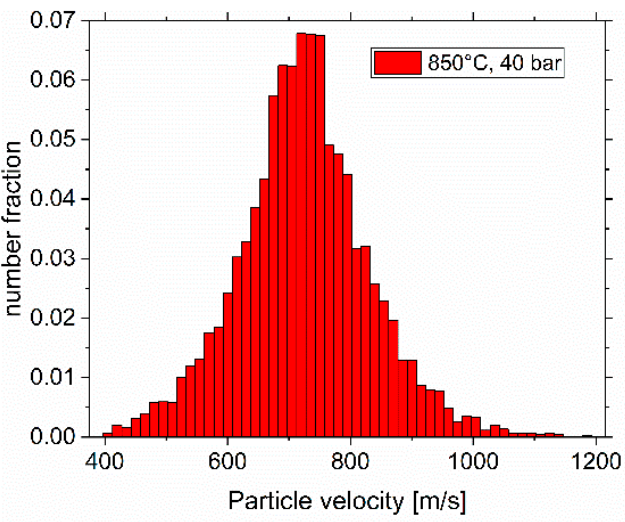

(a)

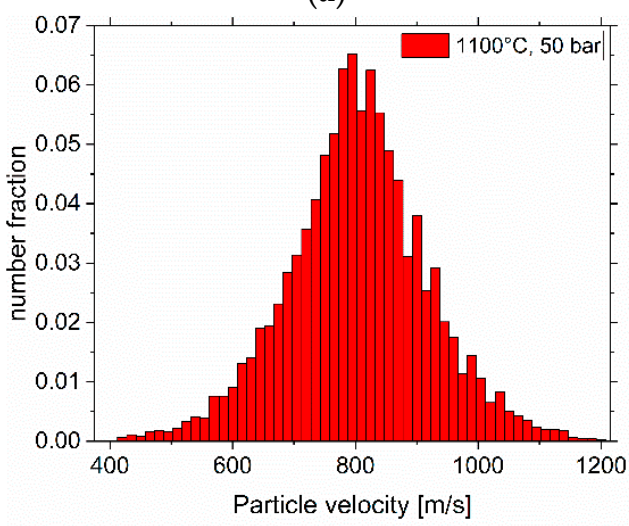

(c)

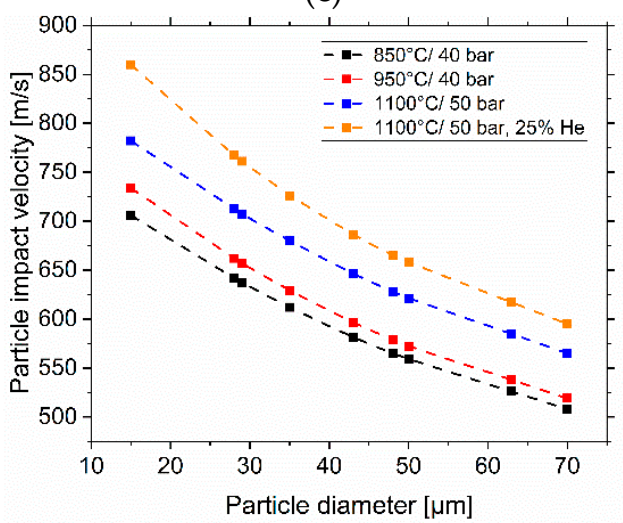

(e)

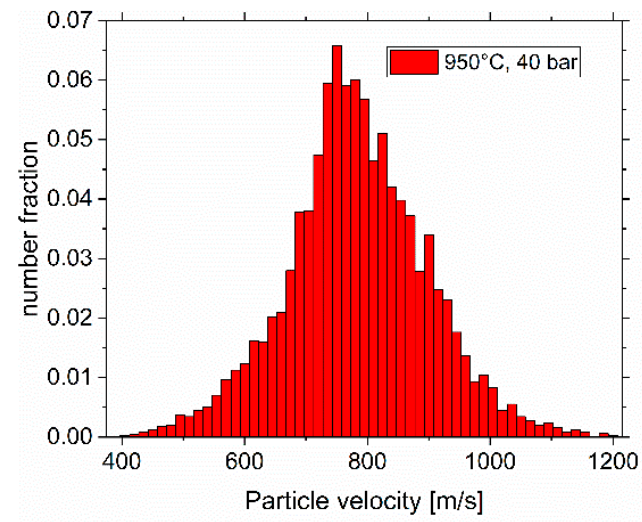

(b)

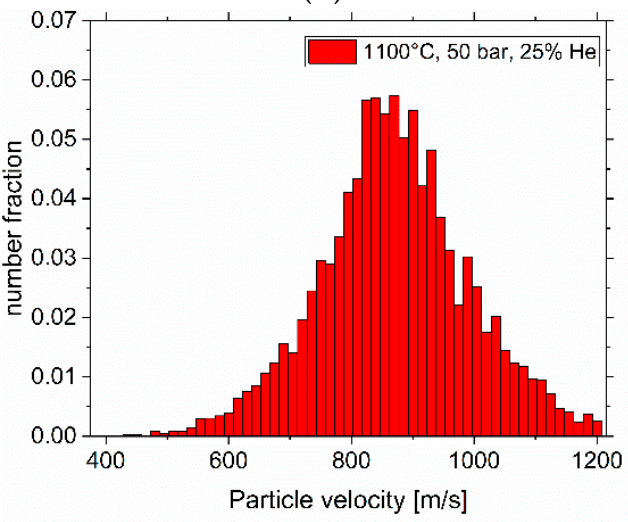

(d)

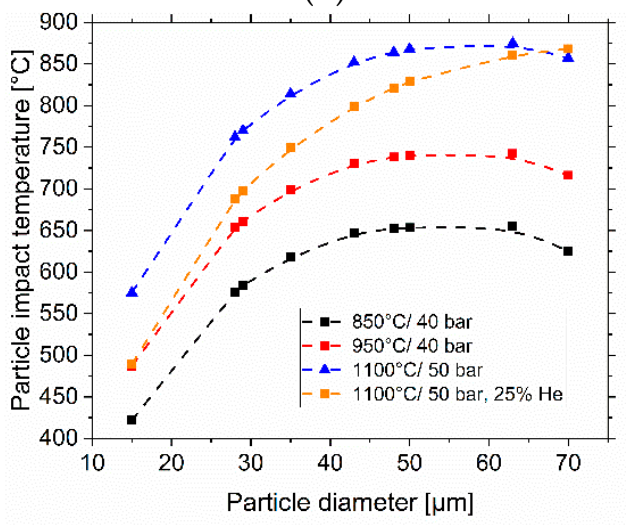

(f)

Figure 2. Particle velocity distributions measured with a cold spray meter: (a) $850{ }^{\circ} \mathrm{C},\left(\right.$ b) $950{ }^{\circ} \mathrm{C}$, (c) $1100{ }^{\circ} \mathrm{C}$ and (d) $1100{ }^{\circ} \mathrm{C}$ and $25 \%$ He. The detailed spray parameters can be found in Table 1. The particle impact velocities and particle impact temperatures depending on particle diameter and spray parameters are presented in $(\mathbf{e}, \mathbf{f})$, respectively. For the calculations, KSS software was used. For certain particle diameters, the values can be found in Table 3.

The particle velocities in Table 3 or Figure 2 were calculated with KSS software, assuming spherical particles. For a more detailed understanding of velocimetry data, it is therefore necessary to experimentally determine the sphericity and to use the corresponding 
drag coefficient for the calculations. Figure 3 shows examples of cross-sections of coating systems produced with different process parameters. A clear contrast between the coloretched austenitic matrix phase and solution-hardened areas without color deposits is still present. While for the coating produced with a process temperature of $850{ }^{\circ} \mathrm{C}$, the phase proportions roughly correspond to those of the powder, a decrease in the proportion of the expanded austenitic phase in the coating structure was observed with an increase in process speed. This can be assumed to be influenced by the different hardness levels in the feedstock powder. The high hardness of particles with the expanded austenitic phase contributes to an increase in the proportion of reflected particles.

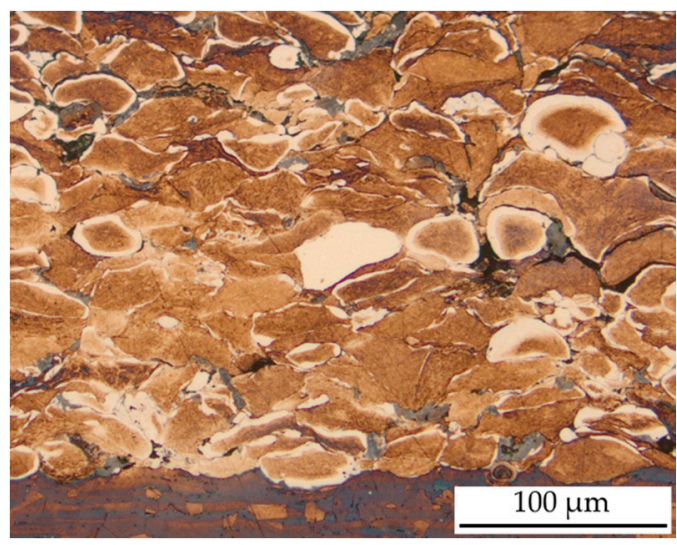

(a)

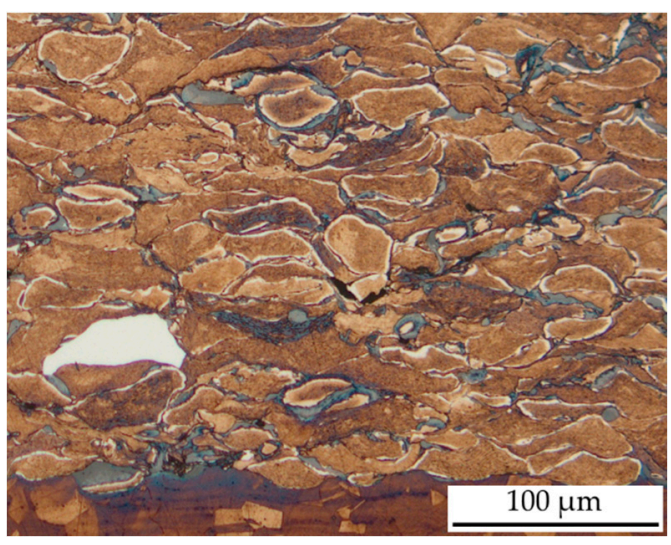

(b)

Figure 3. Optical-microscopic image of a Beraha-II-etched AISI 316L CGS coating using (a) $850{ }^{\circ} \mathrm{C}$ and 40 bar and (b) $1100{ }^{\circ} \mathrm{C}$ and 50 bar with $25 \%$ He in cross-section.

At the same time, the proportion of impurity incorporation of the starting powders in the coating structure increases for a deposition with a process temperature of $1100{ }^{\circ} \mathrm{C}$. This can be explained by the improved formability and low hardness. In contrast to the results for HVOF and APS coatings in Ref. [15], no changes in the phase domains within the individual particles can be observed due to the low thermal load in the process. The nanoindentation measurements showed an increase in hardness for the austenitic phase with increasing process speed. Likewise, the average hardness value increased from $410 \mathrm{HV} 0.005$ for $850{ }^{\circ} \mathrm{C}$, to $460 \mathrm{HV} 0.005$ for $1100{ }^{\circ} \mathrm{C}$ with $25 \%$ He. While only minor variations were observed, a strong gradient was detectable within the expanded austenitic phase. Accordingly, the hardness increased to values between 510-850 HV0.005.

The results of the XRD measurements are shown in Figure 4. Interstitial enrichment is always accompanied by lattice expansion. Due to the heterogeneous treatment condition, the strongest peak occurs for the fcc phase. Characteristic diffraction patterns of precipitates are not detectable.

Due to the heterogeneous phase state, a broad range with no distinct peak appears at lower diffraction angles. This can be assigned to the expanded austenitic phase. Due to the deformation of the particles during processing, the stress states within the grains change. This results in a broadening of the peaks. Due to the higher process speed, the broadening was at its maximum for the coatings deposited with a process temperature of $1100{ }^{\circ} \mathrm{C}$. Although the intensity in the area of the expanded austenitic phase is relatively low, a decrease with increasing process speed can still be observed. This confirms the assumption that the volume fraction of the expanded austenitic phase decreases compared to the initial powder. 


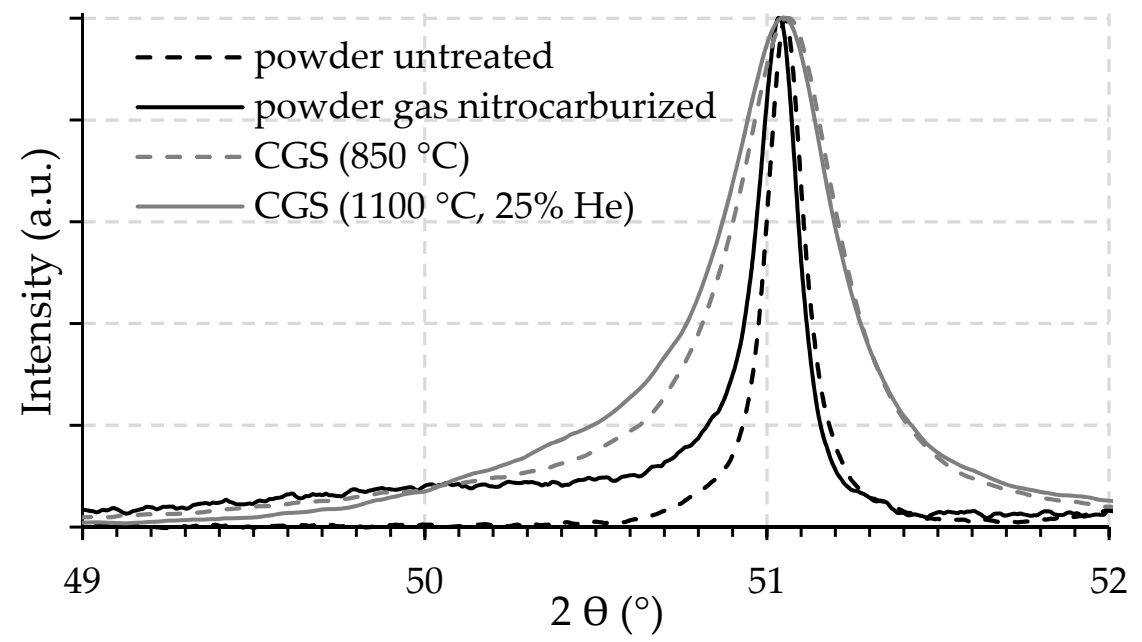

Figure 4. Sections of diffractograms of the untreated and gas-nitrocarburized AISI 316L powders and the CGS coating using $850^{\circ} \mathrm{C}$ as well as $1100{ }^{\circ} \mathrm{C}$ and $25 \% \mathrm{He}$ for the main fcc lattice peak.

The wear resistance of the CGS coatings was characterized under abrasive conditions in the scratch tests, Figure 5. With increasing temperature and pressure, an increase in wear resistance can be observed. The best results were obtained using $1100{ }^{\circ} \mathrm{C}$ and $50 \mathrm{bar}$ with the addition of $25 \%$ He. However, the wear resistance of this coating did not exceed that of the HVOF coating [15]. This can be explained by the decrease in the hardness level of the solution-hardened particles. Nevertheless, the results confirm the potential for the improvement of thermally sprayed austenitic steel coatings by using solution-hardened powder feedstock.

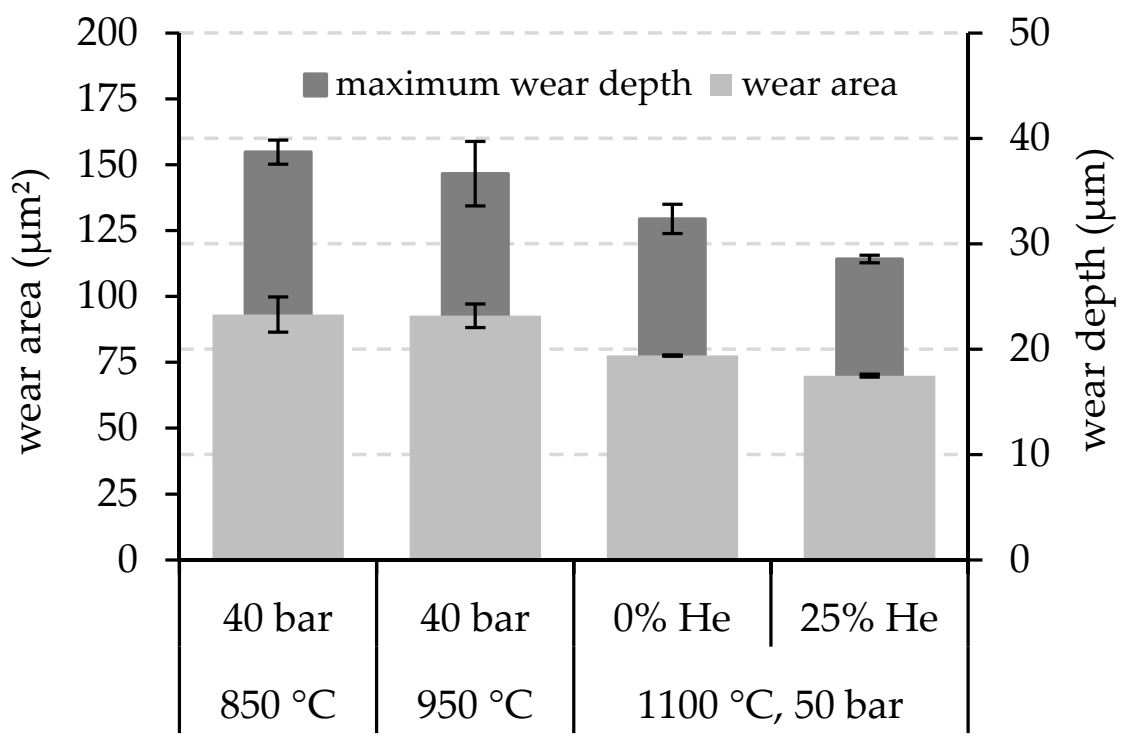

Figure 5. Comparison of the results for wear area and wear depth in scratch tests of CGS coatings in dependence of the process parameters.

The polarization curves also showed a dependence of the spraying parameters on the corrosion behavior, shown in Figure 6. Accordingly, the highest corrosion current densities could be detected in the coating systems that were coated with a process temperature of $850{ }^{\circ} \mathrm{C}$. With an increase in process speed, a continuous decrease in the corrosion current densities could be observed. This can be attributed to the decrease in the volume fractions of the expanded austenitic phase, which exhibits lower resistance compared to the austenitic matrix. 


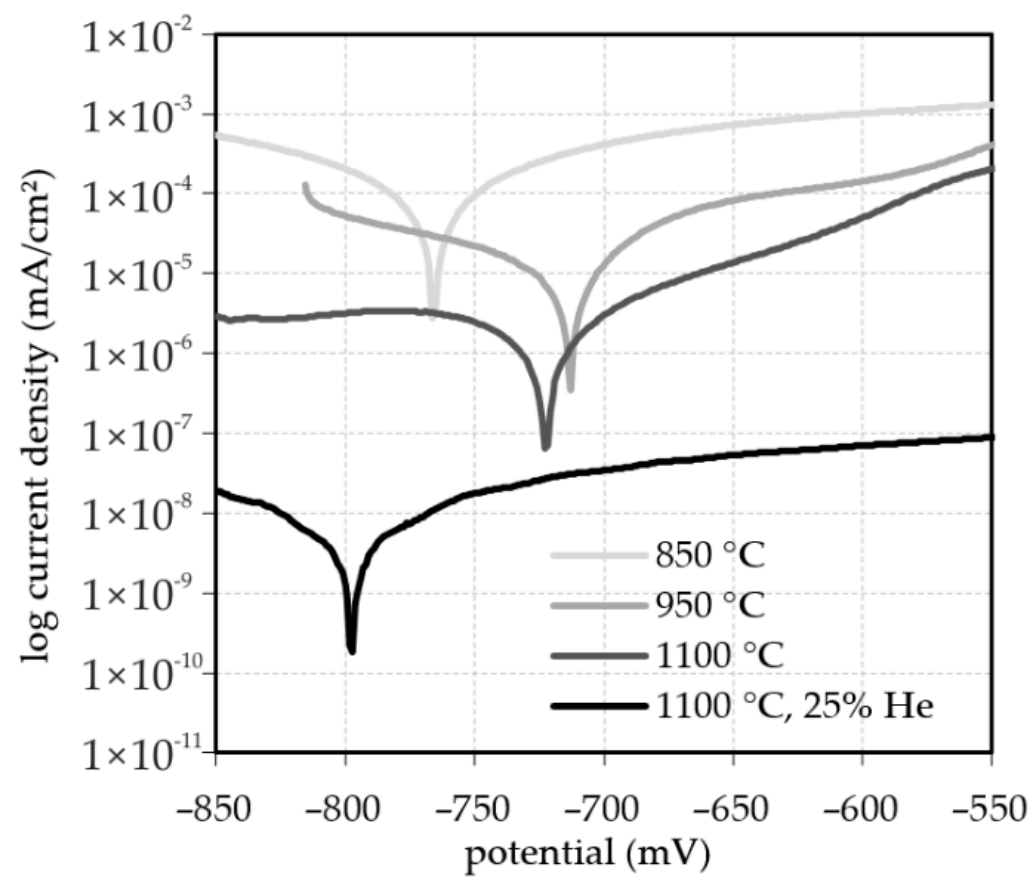

Figure 6. Polarization curves of CGS-sprayed AISI 316L coatings in dependence of the process parameters.

\section{Conclusions}

Solution-hardened AISI 316L powders were successfully processed by cold gas spraying. The deposition of coatings could be achieved with all investigated process parameters. A heterogeneous hardness level of the different phase fractions could be demonstrated. The hardness of the initial austenitic phase increases with the impact velocity. Due to the low thermal energy input in the coating process, the heterogeneous phase structure of the feedstock could be largely preserved for the coatings, while the phase fraction of expanded austenite decreases with increasing impact velocity of the particles. This indicates a reflection effect of hardened particles. An increased proportion of the austenitic phase is associated with a lower corrosion current density in the polarization measurement. Hence, an impairment of the corrosion resistance by the interstitial solid solution phase can be deduced. With increasing kinetic energy, hardness and wear resistance was improved.

The results of this study confirm the general feasibility of the novel process approach for cold gas spraying. The prerequisite for further investigations is the improvement of the quality of the powder treatment. For this, adjustments to the standard industrial routine are necessary. For example, carbon deposition on the surface can be prevented by pure nitrogen enrichment. The development of suitable cleaning steps is another option. Furthermore, a circulation of the powder or a pressure modulation is suitable to achieve a more uniform enrichment medium within the powder bed.

Author Contributions: Conceptualization, T.L., M.L. and J.F.; methodology, T.L., M.L., M.G. and J.F.; validation and investigation, T.L., M.L., M.G. and J.F.; writing-original draft preparation, T.L. and J.F.; writing-review and editing, M.L. and M.G.; project administration, T.L. and J.F. All authors have read and agreed to the published version of the manuscript.

Funding: No funding was received for this study.

Data Availability Statement: Not applicable.

Acknowledgments: The authors thank Niclas Hanisch for conducting the wear tests and Paul Seidel for support in the metallographic investigation and hardness measurement.

Conflicts of Interest: The authors declare no conflict of interest. 


\section{References}

1. Zhao, C.; Li, C.X.; Dong, H.; Bell, T. Low temperature plasma nitrocarburising of AISI 316 austenitic stainless steel. Surf. Coat. Technol. 2005, 191, 195-200. [CrossRef]

2. Bell, T. Current status of supersaturated surface engineered S-phase materials. In Key Engineering Materials; Trans Tech Publications: Zurich, Switzerland, 2008; pp. 289-295. [CrossRef]

3. Borgioli, F. From Austenitic Stainless Steel to Expanded Austenite-S Phase: Formation, Characteristics and Properties of an Elusive Metastable Phase. Metals 2020, 10, 187. [CrossRef]

4. Nestler, M.C.; Spies, H.; Hermann, K. Production of duplex coatings by thermal spraying and nitriding. Surf. Eng. 1996, 12, 299-302. [CrossRef]

5. Wielage, B.; Rupprecht, C.; Lindner, T.; Hunger, R. Surface modification of austenitic thermal spray coatings by low-temperature carburization. In Proceedings of the International Thermal Spray Conference \& Exposition 2011, Hamburg, Germany, 27-29 September 2011; p. 276. Available online: www.researchgate.net/publication/320323004 (accessed on 1 November 2021).

6. Adachi, S.; Ueda, N. Formation of S-phase layer on plasma sprayed AISI 316L stainless steel coating by plasma nitriding at low temperature. Thin Solid Film 2012, 523, 11-14. [CrossRef]

7. Park, G.; Bae, G.; Moon, K.; Lee, C. Effect of plasma nitriding and nitrocarburinzing on HVOF-sprayed stainless steel coatings. J. Therm. Spray Technol. 2013, 22, 1366-1373. [CrossRef]

8. Adachi, S.; Ueda, N. Effect of Cold-Spray Conditions Using a Nitrogen Propellant Gas on AISI 316L Stainless Steel-Coating Microstructures. Coatings 2017, 7, 87. [CrossRef]

9. Adachi, S.; Ueda, N. Wear and Corrosion Properties of Cold-Sprayed AISI 316L Coatings Treated by Combined Plasma Carburizing and Nitriding at Low Temperature. Coatings 2018, 8, 456. [CrossRef]

10. Lindner, T.; Mehner, T.; Lampke, T. Surface modification of austenitic thermal-spray coatings by low-temperature nitrocarburizing In IOP Conference Series: Materials Science and Engineering; IOP Publishing: Bristol, UK, 2016; Volume 118. [CrossRef]

11. Lindner, T.; Kutschmann, P.; Löbel, M.; Lampke, T. Hardening of HVOF-Sprayed Austenitic Stainless-Steel Coatings by Gas Nitriding. Coatings 2018, 8, 348. [CrossRef]

12. Kutschmann, P.; Lindner, T.; Börner, K.; Reese, U.; Lampke, T. Effect of Adjusted Gas Nitriding Parameters on Microstructure and Wear Resistance of HVOF-Sprayed AISI 316L Coatings. Materials 2019, 12, 1760. [CrossRef]

13. Duan, C.; Shen, Y.; Feng, X.; Chen, C.; Zhang, J. Nitriding of Fe-18Cr-11Mn powders using mechanical alloying method through aerating nitrogen circularly. Mater. Sci. Technol. 2016, 32, 1231-1239. [CrossRef]

14. Gnedovets, A.G.; Ankudinov, A.B.; Zelenskii, V.A.; Kovalev, E.P.; Wisniewska-Weinert, H.; Alymov, M.I. Synthesis of Micron Particles with Fe-Fe4N Core-Shell Structure at Low-Temperature Gaseous Nitriding of Iron Powder in a Stream of Ammonia Inorgan. Mater. Appl. Res. 2016, 7, 303-309. [CrossRef]

15. Lindner, T.; Löbel, M.; Lampke, T. Phase Stability and Microstructure Evolution of Solution-Hardened 316L Powder Feedstock for Thermal Spraying. Metals 2018, 8, 1063. [CrossRef]

16. Grujicic, M.; Zhao, C.L.; Tong, C.; DeRosset, W.S.; Helfricht, D. Analysis of the impact velocity of powder particles in the cold-gas dynamic-spray process. Mater. Sci. Eng. A 2004, 368, 222-230. [CrossRef]

17. Assadi, H.; Kreye, H.; Gärtner, F.; Klassen, T. Cold spraying-A materials perspective. Acta Mater. 2016, 116, 382-407. [CrossRef]

18. Rokni, M.R.; Nutt, S.R.; Widener, C.A.; Champagne, V.K.; Hrabde, R.H. Review of Relationship Between Particle Deformation, Coating Microstructure, and Properties in High-Pressure Cold Spray. J. Therm. Spray Technol. 2017, 26, 1308-1355. [CrossRef]

19. Assadi, H.; Gärtner, F.; Stoltenhoff, T.; Kreye, H. Bonding mechanism in cold gas spraying. Acta Mater. 2003, 51, 4379-4394. [CrossRef]

20. Grujicic, M.; Zhao, C.L.; DeRosset, W.S.; Helfricht, D. Adiabatic shear instability based mechanism for particles/substrate bonding in the cold-gas dynamic-spray process. Mater. Des. 2004, 25, 681-688. [CrossRef]

21. Schmidt, T.; Gärtner, F.; Assadi, H.; Kreye, H. Development of a generalized parameter window for cold spray deposition. Acta Mater. 2006, 54, 729-742. [CrossRef]

22. Schmidt, T.; Assadi, H.; Gärtner, F.; Richter, H.; Stoltenhoff, T.; Kreye, H.; Klassen, T. From Particle Acceleration to Impact and Bonding in Cold Spraying. J. Therm. Spray Technol. 2009, 18, 794-808. [CrossRef]

23. Assadi, H.; Schmidt, T.; Richter, H.; Kliemann, J.O.; Binder, K.; Gartner, F.; Klassen, T.; Kreye, H. On Parameter Selection in Cold Spraying. J. Therm. Spray Technol. 2011, 20, 1161-1176. [CrossRef]

24. Al-Mangour, B.; Vo, P.; Mongrain, R.; Irissou, E.; Yue, S. Effect of Heat Treatment on the Microstructure and Mechanical Properties of Stainless Steel 316L Coatings Produced by Cold Spray for Biomedical Applications. J. Therm. Spray Technol. 2013, 23, 641-652 [CrossRef]

25. Xie, Y.; Planche, M.-P.; Raoelison, R.; Liao, H.; Suo, X.; Hervé, P. Effect of Substrate Preheating on Adhesive Strength of SS 316L Cold Spray Coatings. J. Therm. Spray Technol. 2016, 26, 123-130. [CrossRef]

26. Huang, R.Z.; Sun, B.; Ohno, N.; Fukanuma, H. Study on the Influences of DPV-2000 Software Parameters on the Measured Results in Cold Spray, in Thermal Spray 2006: Science, Innovation, and Application (ASM International). 2006. Available online: https:/ / www.researchgate.net/publication/268346796 (accessed on 1 November 2021).

27. Fukanuma, H.; Ohno, N.; Sun, B.; Huang, R. In-flight particle velocity measurements with DPV-2000 in cold spray. Surf. Coat. Technol. 2006, 201, 1935-1941. [CrossRef] 
28. Mauer, G.; Singh, R.; Rauwald, K.-H.; Schrüfer, S.; Wilson, S.; Vaßen, R. Diagnostics of Cold-Sprayed Particle Velocities Approaching Critical Deposition Conditions. J. Therm. Spray Technol. 2017, 26, 1423-1433. [CrossRef]

29. Pattison, J.; Celetto, S.; Khan, A.; O'Neill, W. Standoff distance and bow shock phenomena in the Cold Spray process. Surf. Coat. Technol. 2008, 202, 1443-1454. [CrossRef]

30. Champagne, V.K.; Helfritch, D.J.; Dinavahi, S.P.G.; Leyman, P.F. Theoretical and Experimental Particle Velocity in Cold Spray. J. Therm. Spray Technol. 2011, 20, 425-431. [CrossRef]

31. Huang, R.; Fukanuma, H. Study of the Influence of Particle Velocity on Adhesive Strength of Cold Spray Deposits. J. Therm. Spray Technol. 2012, 21, 541-549. [CrossRef]

32. List, A.; Gärtner, F.; Schmidt, T.; Klassen, T. Impact Conditions for Cold Spraying of Hard Metallic Glasses. J. Therm. Spray Technol. 2012, 21, 531-540. [CrossRef]

33. Suo, X.; Yin, S.; Planche, M.-P.; Liu, T.; Liao, H. Strong effect of carrier gas species on particle velocity during cold spray processes. Surf. Coat. Technol. 2015, 268, 90-93. [CrossRef]

34. Özdemir, O.Ç.; Conahan, J.M.; Müftü, S. Particle Velocimetry, CFD, and the Role of Particle Sphericity in Cold Spray. Coatings 2020, 10, 1254. [CrossRef]

35. Schiller, L.; Naumann, A. Über die grundlegenden Berechnungen bei der Schwerkraftaufbereitung. Vdi Zeits 1933, 77, 318-320.

36. Haider, A.; Levenspiel, O. Drag Coefficient and Terminal Velocity of Spherical and Nonspherical Particles. Powder Technol. 1989, 58, 63-70. [CrossRef]

37. Wadell, H. The Coefficient of Resistance as a Function of Renoylds Number for Solids of Various Shapes. J. Frankl. Inst. 1934. [CrossRef] 